\title{
O FOOTBALL PRECIPITANDO A VIDA ${ }^{1}$ : OS PRIMEIROS ANOS DO ESPORTE BRETÃO EM BELO HORIZONTE (1904-1933)
}

\author{
Recebido em: 13/06/2013 \\ Aceito em: 20/02/2014 \\ Rogério Othon Teixeira Alves ${ }^{2}$ \\ Universidade Estadual de Montes Claros \\ Montes Claros - MG - Brasil \\ Sílvio Ricardo da Silva ${ }^{3}$ \\ Universidade Federal de Minas Gerais \\ Belo Horizonte $-\mathrm{MG}-$ Brasil \\ Georgino Jorge de Souza Neto ${ }^{4}$ \\ Universidade Estadual de Montes Claros \\ Montes Claros - MG - Brasil \\ Sarah Teixeira Soutto Mayor ${ }^{5}$ \\ Universidade Federal de Minas Gerais \\ Belo Horizonte - MG - Brasil
}

RESUMO: Este artigo objetiva compreender os primeiros movimentos do futebol em Belo Horizonte (1904-1933). Procuramos desnudar os primeiros anos do futebol nesta cidade, quais teriam sido as primeiras equipes fundadas e como teria sido a recepção da população frente às competições iniciais e expectativas trazidas nas seções esportivas dos jornais. A pesquisa se baseou em reportagens jornalísticas e em estudos sobre a história do futebol em Belo Horizonte. Buscou explicitar as primeiras partidas e competições, o cotidiano das pessoas e a expectativa trazida pelos jogos de futebol. Nas páginas dos impressos, pudemos notar a evolução do esporte de contornos aristocratas para o popular e o advento do pertencimento clubístico pelo movimento que o futebol proporcionou na formação do torcer, criando momentos que se assemelhavam a uma procissão no trajeto dos torcedores às canchas esportivas da cidade.

PALAVRAS CHAVE: História. Futebol. Jornais.

\footnotetext{
${ }^{1}$ Expressão utilizada por um cronista esportivo da capital mineira para designar a força de penetração social que o futebol alcançara (MINAS GERAES, 1930).

${ }^{2}$ Professor Ms. do Departamento de Educação Física e Desporto/UNIMONTES.

${ }^{3}$ Professor Doutor do Departamento de Educação Física - Universidade Federal de Minas Gerais/UFMG.

${ }^{4}$ Professor Doutorando do Departamento de Educação Física e Desporto/UNIMONTES.

${ }^{5}$ Doutoranda em Estudos do Lazer - Universidade Federal de Minas Gerais/UFMG.
} 


\section{THE FOOTBALL PRECIPITATING THE LIFE: THE EARLY YEARS OF THE BRETON GAME IN BELO HORIZONTE}

ABSTRACT: This article aims to understand the first movements of football in Belo Horizonte (1904-1933). We seek to denude the early years of football in this city, which had been founded the first teams and would have been like the front desk people to initial expectations competitions and brought in the sports sections of newspapers. The research was based on news reports and studies on the history of football in Belo Horizonte. Sought to explain the first few games and competitions, people's daily lives and expectations brought by football games. Pages of printed matter, we note the evolution of the sport of aristocrats contours for the popular and the advent of belonging to a club by the movement that football has provided training in the twist, creating moments that resembled a procession on the path of the fans to the city sports courts .

KEYWORDS: History. Soccer. Newspapers.

\section{Introdução}

Os anos finais do século XIX e início do século XX formam o momento de introdução, no Brasil, dos esportes tidos como modernos, com destaque para o futebol como atividade influenciadora na formação de uma possível sociedade brasileira civilizada (SEVCENKO, 1998). Os estudos mais recentes sobre a história do futebol em Belo Horizonte mostram que o futebol desenvolveu-se em Belo Horizonte de forma semelhante como ocorreu no Rio de Janeiro e em São Paulo. Teria sido o jovem Victor Serpa, filho da aristocracia carioca que, após um período de estudos na Europa e sob a influência da cultura esportiva inglesa, trouxe os equipamentos e as regras do futebol para a cidade, onde cursava a faculdade de Direito (RODRIGUES, 2006; RIBEIRO, 2007).

Em se tratando das cidades do Rio de Janeiro e de São Paulo, há versões de que foi a partir de Charles Miller (em São Paulo) e Oscar Cox (no Rio de Janeiro), que os clubes aristocratas começaram a organizar matchs de football. No entanto, essas versões devem ser observadas com parcimônia, pois privilegiam os centros metropolitanos do país como irradiadores do esporte, sugerindo uma ideia de que o 
futebol tivera uma origem estanque; fatos discutíveis devido à ocorrência de formas de protagonismos relativos a esse esporte em outros locais do país. Nesta perspectiva, não nos interessa, em especial, aprofundar o debate em possíveis origens do futebol brasileiro, mas buscar compreensões sobre o momento em que tal prática esportiva começa a ser anunciada na capital mineira.

Na Belo Horizonte do final do século XIX, recém-inaugurada em 1897, diferentemente de São Paulo e Rio de Janeiro, o futebol era tão novo quanto à própria cidade. Pode-se inferir que futebol e cidade nasceram e desenvolveram-se simultaneamente. Desta forma, é presumível que, quando o futebol deu seus primeiros passos a cidade ainda "engatinhava" e, possivelmente, alguns improvisos foram inevitáveis. Parte da juventude citadina local, receptível a tudo que fosse moderno e europeu, não demorou a fundar equipes no afã da febre esportiva no Brasil republicano, ansioso por tudo que a moderno cheirasse.

Após os primeiros anos pueris e amadores, os futebolistas foram se organizando e não demoraram a se encorpar com equipes mais bem preparadas. Com o passar de alguns anos, mesmo conquistando a aceitação de setores da sociedade como escolas e associações esportivas, também passaram a conviver com as críticas de intelectuais que não acreditavam nas supostas benesses físicas e morais da nova prática esportiva. Paulatinamente, o futebol começou a fazer parte da vida dos cidadãos brasileiros e o veículo propagador da atividade moderna mais cobiçada pela população foi o jornal impresso.

Nos anos 1920, Belo Horizonte já detinha boa circulação de jornais, e eles não se omitiam sobre os esportes, muito menos sobre o futebol. Através deles, notamos o quão grande era o futebol na vida do seu cidadão. Observamos que ir ao campo de jogo 
e acompanhar uma partida não tinha um fim em si mesmo; esse momento transcendia o mero espetáculo e promovia à assistência ${ }^{6}$ momentos de excitação e extravasamento que, segundo os impressos, nenhuma outra atividade local permitia.

A seção esportiva dos periódicos contribuiu para que equipes como Atlético Mineiro, América e Palestra Itália fossem alçados à condição de predileção afetiva dos seus habitantes, formando suas "torcidas". Referindo-se à cidade de Belo Horizonte, Souza Neto (2010, p.48) diz que "os últimos anos da década de 1910 e a primeira metade da década de 1920 representaram um período estruturador para a composição da prática social denominada "torcida", Neste período, notamos o surgimento de um universo futebolístico mais estruturado, com a organização de torneios. A partir destas práticas, começou-se a nutrir o sentimento de rivalidade esportiva, pois os jogos não mais tinham uma assistência pacata, já que os espectadores passaram a pertencer a algum clube.

Enfim, a partir da análise de bibliografias e jornais que tratam da história do futebol em Belo Horizonte, procuramos desnudar os primeiros anos de sua prática nesta cidade, atendo-nos, principalmente, às primeiras equipes fundadas e em como teria sido a recepção do povo frente às competições iniciais e as expectativas trazidas nas seções esportivas dos jornais. Estes, como aponta Vieira (2007, p.13), podem permitir uma "ampla visada da experiência citadina: dos personagens ilustres aos anônimos, do plano público e privado, do político ao econômico, do cotidiano ao evento [...]". A partir da imprensa, ressalta o autor, podemos encontrar projetos políticos e visões de mundo e vislumbrar "a complexidade dos conflitos e das experiências sociais".

\footnotetext{
${ }^{6}$ A assistência designa a ocorrência de um público assistente, notadamente, constituído sem nenhuma vinculação afetiva com um ou outro clube de futebol (SOUZA NETO, 2010).
} 
Assim, tornaram-se objeto desta pesquisa, o jornal Minas Geraes, o Estado de Minas, o Diario de Minas e o Araldo Italiano. Periódicos que nos permitiram situar o futebol para além de suas especificidades esportivas, sobretudo, enquanto manifestação imersa na cultura citadina da capital mineira.

\section{O nascedouro do futebol horizontino}

Ribeiro (2007) e Vilhena (2008) relatam que em uma das alamedas do Parque Municipal da cidade "foi realizado o primeiro ensaio futebolístico, em três de maio de 1904" e que equipes foram criadas e realizavam seus treinos nele, caso da primeira agremiação de futebol da cidade, o Sport Club Foot-ball, que nasceu em 10 de julho de 1904. Ainda neste ano, Couto (2003, p.41) registra as fundações do Plínio F.C., do Club Athletico Mineiro (que não é o precursor do atual Clube Atlético Mineiro), do Vespúcio e do Colombo. Estas equipes disputaram o primeiro campeonato de futebol da cidade no mesmo ano.

A versão mais divulgada nas bibliografias correntes sobre o futebol mineiro é a de que o estudante Victor Serpa foi o maior incentivador do futebol em Belo Horizonte. Ele trouxe da Suíça e do Rio de Janeiro as experiências atléticas com pretensões modernas e as concepções iniciais do association (RODRIGUES, 2006; RIBEIRO, 2007). É importante observar que, após sua morte em 17 de janeiro de 1905, o desenvolvimento do esporte foi arrefecido. Com o entusiasmo diminuído e a não continuação do Campeonato disputado no ano anterior, o futebol desandou para o fechamento de todas as agremiações no ano de 1907 (RIBEIRO, 2007).

O ano de 1908 significou o recomeço do futebol em Belo Horizonte. Rodrigues (2006, p.70) relata que uma nova fase na constituição do futebol na cultura urbana da 
cidade reiniciou-se em 1908 e se estendeu até 1915. Neste segundo período, afirma Silva (2012, p.70), o interesse pelo futebol encontrou uma cidade que se transformava rapidamente. Este movimento foi se tornando mais consistente e, nos anos seguintes, um grande número de novos clubes apareceu, com destaque para os seguintes:

\section{Club Athletico Mineiro}

Em 25 de março de 1908, um grupo de jovens, em sua maioria, filhos de médicos, advogados e altos funcionários públicos de tradicionais famílias mineiras, fundaram, em reunião no Parque Municipal o Athletico Mineiro Futebol Club. Em 25 de Março de 1913, dia em que se comemorava o quinto aniversário do clube, uma assembleia geral foi convocada e o time ganhou um novo nome: Club Athletico Mineiro. Seu primeiro estádio foi construído em terreno cedido pela prefeitura na Av. Paraopeba (atual Av. Augusto de Lima) (ZILLER, 1997; COUTO, 2003).

\section{Yale Athletic Club}

Em agosto de 1910 surgiu o Yale, que se anunciava numa concepção esportiva mais abrangente. Seu intento não era só incrementar o futebol, mas também as diversões na cidade. O Yale passaria a ser um agente promotor e difusor do esporte na cidade, organizando festivais esportivos com o intuito de promoção social e convívio público (RODRIGUES, 2006, p.173; RIBEIRO, 2007, p.66; SOUZA NETO, 2010, p.31). Sua maior conquista foi o vice-campeonato mineiro de 1919.

\section{America Foot-ball Club}

O América nasceu a 30 de abril de 1912, ao estilo do Clube Atlético Mineiro. Surgiu numa reunião nas imediações da Praça da Liberdade, pela vontade de garotos praticantes de futebol no parque municipal, que não passavam de 13 anos de idade, 
filhos da mais distinta elite da cidade. Seu grande feito histórico foi o domínio absoluto de conquistas no Campeonato local de 1916 a 1925 (COUTO, 2003; RODRIGUES, 2006).

\section{Societá Sportiva Palestra Italia}

Um evento que simboliza a expansão e efervescência do futebol na Belo Horizonte dos anos 1920 foi a fundação da Societá Sportiva Palestra Italia. Pelo desejo da colônia de imigrantes italianos houve um movimento diferente dos acontecidos, por exemplo, com os tradicionais Atlético Mineiro e América, pois estes tiveram perfis marcadamente nacionais. Era desejo dos italianos e seus descendentes, em sua maioria comerciantes, artesãos, trabalhadores da construção civil, operários e alguns empresários e industriais, o pertencimento a um clube essencialmente italiano. No dia 02 de janeiro de 1921, inspirados no estatuto do Palestra Italia paulistano de 1914, fundaram a Societá Sportiva Palestra Italia. Se de início seus fundadores, na média, não tinham nível socioeconômico elevado, logo se constituiu numa equipe competitiva (COUTO, 2003; RIBEIRO, 2007; SILVA, 2012).

\section{Das primeiras competições: impactos e percepções}

Em 1914, de acordo com Rodrigues (2006); Ribeiro (2011) e Souza Neto (2010), foi disputado no Prado Mineiro ${ }^{7}$, o primeiro torneio da segunda fase do futebol na cidade: Taça Bueno Brandão. Participaram os primeiros teams do Athletico, Yale e America, sagrando-se campeão o Athletico. Esse torneio foi um marco impulsionador de

\footnotetext{
${ }^{7}$ O Prado Mineiro se tornaria a primeira construção erguida com a configuração de estádio na cidade de Belo Horizonte. Primeiramente construído para abrigar as corridas de cavalo, o Prado sucumbiria à força do crescente apelo popular que o futebol ganhara em início dos anos 1910.
} 
uma Liga de Futebol na cidade e nele já foi possível observar um comportamento mais acirrado da torcida com a assistência, nutrindo uma admiração e preferência por um dos clubes. No ano seguinte, deu-se início o primeiro campeonato oficial da cidade, embrião do atual Campeonato Mineiro.

A aceitação do futebol como esporte preferido em detrimento aos outros pôde ser percebida na interferência deste na dinâmica da cidade. A fundação de equipes e organização de torneios expôs a predileção da população pelo futebol, notada na numerosa assistência aos jogos e identificação com as equipes. A tradicional sociedade mineira ia se rendendo ao futebol (MOURA, 2010).

De início, apropriado pela burguesia, o esporte serviu como uma atividade de distinção e progressão social revestido de valores aristocráticos do ócio, do adestramento militar e do sportsmanship (cavalheirismo, imparcialidade e lealdade). Observa Sevcenko (1998) que, se inicialmente o futebol teve formato aristocrático, restrito à elite das cidades, logo se veria assimilado pela gente menos abastada e levantaria interesses variados pelas cercanias das cidades, pois era visto como uma forma de galgar posições de privilégio na sociedade.

No Brasil do início do século XX desencadeou-se, principalmente nas décadas de 1920 e 1930, uma febre esportiva motivada pelas supostas benesses físicas e morais advindas do esporte (SEVCENKO, 1998). Certamente, o futebol nessa época já se mostrava como uma das atividades mais praticadas e admiradas pela população, inicialmente pela aristocracia e, depois, reinventada pelas classes menos favorecidas. Guterman (2009, p.50) sustenta a premissa de que a "[...] a ruptura do futebol, de esporte de elite para esporte de massa, de esporte amador para esporte profissional, se 
daria mais concretamente nos anos 1920, quando a Primeira República já dava sinais de desgaste em razão de seu desprezo atávico por tudo o que cheirasse a povo”.

Com o passar dos anos, o futebol se constitui como poderoso evento de massas, conforme sugere Pereira (2000, p.109).

Construído a princípio por seus próprios praticantes como símbolo de uma identidade restrita, o jogo transformava-se em um poderoso evento de massas - em um processo que pode nos ajudar a entender o movimento que acabaria por fazer do futebol um meio de identificação entre amplas parcelas da sociedade.

Já não se podia desprezar o poderio social, político e econômico que uma partida de futebol representava. Dos anos 1920 em diante, o cenário do futebol no Brasil e no mundo já tinha organização concreta. Já havia sido introduzido oficialmente nas Olimpíadas de Londres de 1908 e, em 1930, seu primeiro campeonato mundial, organizado pela FIFA ${ }^{8}$, aconteceu no Uruguai.

Em Belo Horizonte, não fora diferente. Atividades esportivas - mais destacadamente o futebol - não demoraram a fazer parte da vida da cidade. A escalada da popularização do esporte culminaria com o boom desportivo dos anos 1920, fenômeno observado em várias partes do mundo moderno e capitalista do pós-Primeira Grande Guerra Mundial (RODRIGUES, 2006; SEVCENKO, 1998).

Silva (2012) lembra que os sinais de maior apropriação do futebol na cidade de Belo Horizonte começaram a surgir no início da década de 1910, tornando-se cada vez mais evidentes. O jovem Pedro Nava, que seria anos mais tarde um importante escritor e memorialista brasileiro, estudou no Colégio de origem inglesa Anglo-Mineiro, nos dois anos de existência do mesmo - 1914/15. Este educandário se popularizava entre os meninos de Belo Horizonte por ter em seu currículo a cátedra e o professor titular de futebol: "colégio sem latim, nenhum catecismo e excesso de esportes. Era futebol

\footnotetext{
${ }^{8}$ Fédération Internationale de Football Association - fundada em 1904.
} 
demais" (NAVA, 1974, p.118). Era corpo demais! Nava descreve na prática a influência dos ingleses no futebol mineiro; os estrangeiros do Anglo "fizeram sentir o seu jeito na técnica, nas regras, no espírito esportivo, na 'gentlemanhood', no treinamento, na seleção do material e até nos uniformes dos jogadores" (NAVA, 1974, p.135).

Na Belo Horizonte das décadas de 1920 e 1930, o futebol já era veiculado como o divertimento mais popular da cidade. O campeonato de futebol local - Campeonato da Cidade - chamava a atenção pela quantidade de interessados e clubes envolvidos, ainda amadores. O crescimento do interesse do público levou a um aumento da atenção jornalística pelo esporte, com a publicação constante de matérias, o surgimento de colunas fixas nos grandes jornais e até mesmo de periódicos especializados. No imaginário da cidade já habitava correntemente o futebol. A imprensa, sabedora e espelho ${ }^{9}$ dos costumes de um povo, situava-se sabiamente nesse cenário.

Mais intensamente, a partir da década de 1920, Moura (2010) diz que a imprensa começou a assumir seu papel de promotora dos jogos e de formadora de opinião. A assistência consumia a diversão esportiva das mais diferentes formas. "Aos poucos, o ambiente refinado dos primeiros anos vinha sendo substituído por um clima de competição e revanchismo nos anos 1920" (SILVA, 2012, p.71), fomentado pela crescente circulação de notícias.

O jornal Araldo Italiano (1923), publicado para a colônia, deu ampla cobertura às ações do clube exclusivamente seu: A “fiorente" Societá Sportiva Palestra Italia crescia dia após dia graças a boa vontade dos seus mais de 300 sócios. Seu progresso foi percebido em apenas dois anos e meio de existência e todo italiano queria saber quão grandiosa era a sua agremiação, crescendo ao exemplo do Palestra Itália paulistano.

\footnotetext{
${ }^{9}$ Viera (2007, p.16) sugere que compreendamos o jornal pela metáfora do espelho. Ele reflete a realidade, mas com distorção e refração, cabendo ao pesquisador estudar "o funcionamento desse sistema de espelhamento que, discursivamente, confere sentidos às coisas, às ações, às palavras ditas e não ditas".
} 


\begin{abstract}
"Societá Sportiva Palestra Italia" - Questa fiorente societá sportiva, della quale é presidente l'egregio giovane, sr. Alberto Noce, progredisce giorno per giorno, data La straordinaria buona volontá della direzione tutta e dato l'entusiasmo dei suoi 300 soci. Se volessimo passare in rivista Il progresso fatto in questi due anni e mezzo d'esistenza, vedremmo ancora uma volta Che in tutte Le cose qnando l'italiano vuole as esser grande. Fondata Il 2 gennaio 1921, come conseguenza Del sucesso ottenuto dalla omonima di San Paulo, che riusci campione de S. Paolo del 1920; ottenne súbito dalla colônia italiana quell'appoggio morale e materiale che erano necessari al suo rapido sviluppo [...] (ARALDO ITALIANO, 1923).
\end{abstract}

Enfim, o futebol, uma atividade concebida e organizada pelos ingleses, transformara-se, no Brasil, em uma peste que infestava as cidades e que se alastrava pelos campos do Brasil, como anunciara dramaticamente Mário de Andrade em sua obra prima Macunaíma, publicada nas primeiras décadas do século XX (ANDRADE, 1993).

No entanto, originariamente aristocrático e, paulatinamente, popularizado, o futebol também foi alvo de críticos que não o viam como atividade civilizada. Coryntho da Fonseca ${ }^{10}$ (1930), expôs toda sua contrariedade quanto aos acontecimentos de uma partida de futebol. Não parecia crível para ele, precisar-se de aparatos policiais repressivos para “[...] desatar sururus ${ }^{11}$ ou para garantir os 'referees ${ }^{12, "}$. Da assistência notada por Fonseca já não se podia “[...] apurar selecções esmiuçadoras e nem dos proprios desportistas que tinham a obrigação funccional do bom exemplo de correcção de maneiras". Em um trecho mais destacado da nota, lia-se:

O FOOTBALL NÃO MERECE O TITULO DE DESPORTO - [...] Não conheço, aqui, nem um caso de uma "court" de tennis ser invadida pela assistencia, impondo a introducção da cavallaria policial para desatar sururus ou para garantir os "referees" nem, ainda menos, para conter os próprios jogadores atracados aos bofetões e ponta-pés. [...] Não ha partida de football que não exija a comparencia de um policiamento reforçado. [...] Nos campos

\footnotetext{
${ }^{10}$ Educador brasileiro dos anos 1920 no Rio de Janeiro, admirador dos métodos americanos de educação, foi defensor da pedagogia da politecnia. Autor de A escola ativa e os trabalhos manuais.

${ }^{11}$ Termo utilizado pelos periódicos para se referir às confusões e brigas ocorridas dentro e fora dos campos de futebol.

12 Referees representava um dos muitos anglicismos ligados à narrativa futebolística periódica, e designava os árbitros das partidas.
} 
de football, em todos os dias de partida, o policiamento nunca é, platonicamente, preventivo. Tem de ser repressivo. O "sururu" é do programma, não só entre o publico assistente, em que, de resto, não se podem apurar selecções esmiuçadoras, mas entre os proprios desportistas que tinham a obrigação funccional do bom exemplo de correcção de maneiras. [...] Um desporto que suggere pensamentos de morte, que provoca, na multidão, gritos de lynchamento, não pode ter, não merece ter o nome de desporto, de meio louvavel para o desenvolvimento physico da raça (FONSECA, 1930, p.14).

Outra ideia que se mostraria contrária, considerando o futebol no Brasil, foi protagonizada pelo escritor Graciliano Ramos, em crônica publicada no início dos anos 1920. A nota profética narrava: O futebol "[...] vai ser, por algum tempo, a mania, a maluqueira, a ideia fixa de muita gente. [...] Temos esportes em quantidade. Para que metermos o bedelho em coisas estrangeiras? O futebol não pega, tenham certeza". Porém, o futebol se firmou e não foi “[...] um entusiasmo de fogo de palha capaz de durar bem um mês" (RAMOS, 1994). Soares e Lovisolo (1997, p.17), afirmam que a profecia de Graciliano falhou e sintetizam: o futebol popularizou-se “[...] talvez por ser um dos poucos espaços sociais que nasceu para as elites e do qual as camadas populares se apropriaram rapidamente".

Alguns intelectuais brasileiros trataram o futebol com parcimônia, por considerarem-no eurocêntrico ou demasiado violento; outros o defenderam ardentemente como parte da cultura nacional (LEVINE, 1982). Literatos modernistas como Olavo Bilac, Coelho Neto, Antônio de Alcântara Machado e Lima Barreto fizeram observações intelectualizadas da nova moda esportiva.

Coelho Neto, ardoroso adepto, tomou a defesa e a propaganda do esporte como reflexo de um novo estilo de vida. Bilac procurou explorar o aspecto moral do "esporte bretão". Alcântara Machado registrou o pitoresco das partidas, contando gostosamente como a torcida paulista reagia. Para Lima Barreto o futebol era mais um modismo importado, coisa degradante, algo antipatriótico (BERTOLLI FILHO e MEIHY, 1982, p.105).

A imprensa de Belo Horizonte mais apoiou do que detratou o futebol; a partir dela, pode-se observar que consumir o futebol diariamente passou a fazer parte da vida 
da cidade. A expectativa para os embates, as escalações, as previsões, as brigas entre jogadores e entre a assistência, o relato das jogadas principais, os ídolos, as críticas, habitaram as reportagens dos periódicos em suas seções esportivas.

\section{A cidade e o futebol: "é preciso não parar"}

Com o desenvolvimento expressivo do futebol, o interesse da imprensa esportiva foi evidente, tanto que em 1919 foi criada a Associação Mineira de Chronistas Sportivos (AMCS), órgão que seria reconhecido pela Liga Mineira de Sports Athleticos ${ }^{13}$ no mesmo ano (RODRIGUES, 2006, p.285).

A AMCS foi uma promotora de eventos esportivos e, segundo seu estatuto, tinha por fim “cooperar para a difusão e engrandecimento do desporto, estimular a sua prática por todos os meios ao seu alcance" (RIBEIRO, 2007, p.94), sendo o futebol o seu preferido. Ela não se furtava em anunciar e promover os "seus" torneios no Prado Mineiro, como o Torneio da Imprensa de abril de 1920. No Diário de Minas:

\footnotetext{
Os apreciadores do popular sport bretão vão ter hoje, com o Torneio de football, promovido em homenagem à imprensa, pela Associação Mineira dos Chronistas Desportivos, um dos seus melhores dias. Leva-nos a affirmar o enthusiasmo pouco commum que se vêm notando nas rodas de sport da capital [...] (DIARIO DE MINAS, 1920, p. 2).
}

No dia 17 de abril de 1921, aconteceu, no Prado Mineiro, um torneio que recebeu o nome de Taça A.M.C.D, denotando o prestígio da entidade e o valor a ela abonado. Em jogo preliminar do torneio bater-se-iam os clubes que futuramente protagonizariam o maior clássico do futebol de Belo Horizonte: Athletico X Palestra.

O torneio em questão foi anunciado pelos jornais Minas Geraes e Diário de Minas. Contudo, a ênfase dada pelo último, para o jogo Athletico X Palestra foi

\footnotetext{
${ }^{13}$ Em 1915 foi fundada a Liga Mineira de Esportes Atléticos e realizado o primeiro campeonato oficial da cidade (COUTO, 2003, p.99).
} 
surpreendente, visto que era um jogo inédito; “[...] em verdade, de despertar curiosidade e interesse”. Além disso, o Palestra Itália, diria o jornal, “já manifestou a sua força e pretende trilhar em Minas a mesma róta do valoroso campeão da Paulicéa" (DIARIO DE MINAS, 1921, p. 2).

Em notas, o Minas Geraes destaca:

A Associação Mineira de Chronistas tem trabalhado ativamente em favor dos próximos jogos America X Luzitano e Athletico X Palestra, promovidos nesta Capital pela mesma sociedade (MINAS GERAES, 1921, p. 6).

Em jogo preliminar, bater-se-ão os quadros do Athletico e Palestrina, sendo oferecido ao vencedor uma rica medalha de ouro (MINAS GERAES, 1921, p. 6).

Já no Diário de Minas, lia-se:

\begin{abstract}
Alcançou o mais completo sucesso o festival promovido pela Associação Mineira de Chronistas Desportivos anteontem realizado no Prado Mineiro. As vastas archibancadas encheram-se de apreciadores do popular sport bretão, e não era menos a concorrência nas geraes, dando-nos a impressão agradável de que se vae iniciando magnificamente a temporada sportiva de 1921 (DIARIO DE MINAS, 1921, p. 2)
\end{abstract}

No ano seguinte, a AMCS voltaria a organizar no Prado Mineiro outro torneio, marcando o encerramento da temporada desportiva de 1922. Athletico e Palestra, mais uma vez, fariam o jogo preliminar disputando a Taça Concordia. A principal contenda, Taça Dr. Jair Mendes, seria disputada pelas extintas agremiações do Luzitano e Yale.

TORNEIO DA IMPRENSA. - Está definitivamente organizado o brilhante festival com que a Associação Mineira de Chronistas Desportivos encerrará a temporada desportiva deste anno, amanhã, no campo do Prado Mineiro. [...] Ás 14 horas medirão forças as esquadras do Palestra e Athletico, para conquista da "Taça Concordia” (MINAS GERAES, 1922, p. 7).

TORNEIO DA IMPRENSA. - [...] Jogo principal Lusitano X Yale. Nos outros jogos, o $2^{\circ}$ quadro do Lusitano venceu o primeiro do Hellenico, conquistando a taça "dr. Jair Mendes", e o Athletico e o Palestra empataram por 2 X 2 (MINAS GERAES, 1921, p. 7). 
Consequentemente à ação da AMCS de badalar o futebol, também se promoviam as equipes e seus jogadores. $\mathrm{O}$ cidadão que ia ao jogo fazia parte de uma estrutura peculiar: a expectativa para o jogo, o deslocamento para o Prado e as relações sociais no campo. A afinidade por uma agremiação e/ou jogador envolviam os sujeitos participantes de significados e sentimentos próprios do palco do futebol. A simples ação de assistir ao jogo começava a dar lugar ao pertencimento, ao torcer por um dos lados.

Na Belo Horizonte dos anos 1920, Moura (2010, p.34) expõe a existência de uma rotina que tinha como mote o futebol e o enaltecimento do torcer enquanto importante manifestação social.

[...] as pessoas, nos dias de jogos dos seus times, construíam ou ressignificavam os costumes, os limites e as convenções sociais. Assim, os habitantes da cidade inventavam novas formas de ocupação da mesma, de relacionamentos com os outros e de usufruírem dos espaços públicos. Uma "dose" de permissividade também podia ser evidenciada nos momentos de comemoração dos torcedores. Coisas que as pessoas não fariam no dia-dia passaram a ser possíveis nos arredores dos campos de futebol e nas horas de celebração das vitórias.

A seção Vida Sportiva do Diario de Minas de 1921 alertou para o fato de se ficar sem o futebol por um longo tempo na cidade: É preciso não parar!, exclamava o periódico. O período posterior à temporada do futebol não podia tirar da torcida os momentos de prazer que o movimento esportivo proporcionava a Belo Horizonte. Os dirigentes deveriam diminuir "[...] as ferias sportivas com um ou outro encontro de interesse. $[\ldots]$ para se não perder o costume... de ir ao Prado”.

É preciso não parar [...]

Observa-se frequentemente em Bello Horizonte, em nosso movimento sportivo, o seguinte: algum enthusiasmo, algumas festas durante o campeonato. É terminar este, e logo o nosso mundo sportivo cáe num desanimo, num indifferentismo nunca visto. Já estamos prevendo para agora uma época assim. Ainda falta um jogo para a decisão definitiva da temporada anual, e a impressão que tem é de que acabou o foot-ball em Bello Horizonte! Ora, isso é justamente o que não deve acontecer. Os dirigentes do desporto, na liga e nos clubs proporcionarão horas de prazer á nossa torcida si conseguirem amenisar as indolentes ferias sportivas com um ou outro encontro de interesse. Quando se não tratasse de uma necessidade evidente para o incremento sportivo do nosso meio, ao menos seria para se não perder 
o costume... De ir ao Prado, já tão perdido nestes tempos (DIARIO DE MINAS, 1921, p. 2).

Esperar por um jogo de futebol merecia, assim, destaque da imprensa belohorizontina, e se não houvesse jogo no final de semana a imprensa notava. O período sem partidas na cidade assustou o impresso O Estado de Minas de 4 de janeiro de 1930, trazendo a preferência da população pelo futebol e o choque com o fato de não ter havido jogo no final de 1929.

O ano de 1929 acabou sem uma partida sensacional de foot-ball. E Bello Horizonte inteirinha - que não esconde a sua preferência escandalosa pelo Sport - ficou triste com essa falha. A gente só via o pessoal queixando-se pelas ruas: o que é que eu vou fazer para encher esse domingo? Passear no parque? Tem muita poeira. Ir à matinée? Morre-se abafado lá dentro. E ninguém acha o que fazer (ESTADO DE MINAS, 1930, p. 5).

Agitação popular e ansiedade estavam expressos em trechos da crônica esportiva do Minas Geraes (1930, p. 11). Notamos, no jogo Palestra e Atlético, a euforia trazida pelo domingo de futebol regada à insônia, indignação com a lotação dos carros e das arquibancadas. A raiva cessava com a chegada da hora solene do jogo, “[...] poderosa, destruindo todas as attenções dispersas, fazendo esquecer as contrariedades da vida".

[...] O povo tinha pressa de ver si o Athletico, naquelle dia bellissimo de antehontem, conseguiria desfazer a influencia da sua falta de sorte tradicional. Os retardatarios sahiram da egreja ás onze horas e correram para o campo. As archibancadas já estavam cheias. Vinte mil pessoas. Ninguem contou. Mas toda a gente calculava assim. - Eu previa esta assistencia. Eu sabia que hoje isto ia ficar assim. Tudo apertado. A hora do jogo veiu, poderosa, destruindo todas as attenções dispersas. Fazendo esquecer as contrariedades da vida (MINAS GERAES, 1930, p. 11).

Os dias de jogos, os melhores dias do anno, normalmente aos domingos, não eram dias quaisquer, a cidade se agitava. A dinâmica seguia rituais comandados pela bola. Tal inquietação se notava nos dias e horários anteriores aos jogos de maior apelo, como num América e Palestra de 1930, descrito noutra crônica esportiva do Minas 
Geraes (1930, p.13), que narrava um estádio lotado, a família mineira presente, o torcedor descontrolado, ansioso pelo início: "o football precipitando" a vida dos seus fãs.

[...] A archibancada começou então a encher-se. - Eu fui á missa das dez. depois, perdi um bonde. Quase não almocei. Estava sem vontade. Vocês acham que o Palestra vae bater? Domingos de Bello Horizonte... Não! Domingos de campeonato. Os melhores dias do anno. A gente vivendo depressa. Gritando. Horas de ansiedade, de soffrimento, de alegria... Ambições fracassadas em um minuto. Victorias imprevistas. Vinganças. Os olhos em cima do campo. A multidão descontrolada. $\mathrm{O}$ football precipitando a vida. Insultos e provocações. $\mathrm{O}$ tempo fechando. $\mathrm{O}$ barulho maior. A população sportiva de Bello Horizonte (MINAS GERAES, 1930, p. 13)

Já na edição do Estado de Minas, de $1^{\circ}$ de março de 1931, após anunciar, com grande entusiasmo, a partida entre o tri-campeão da cidade e o Club Athletico Mineiro para a tarde do mesmo dia no campo do Palestra, divulgou-se, também, a frequência e local de partida dos bondes que atenderiam aos torcedores que seguiriam para o prélio válido pelo Campeonato Mineiro.

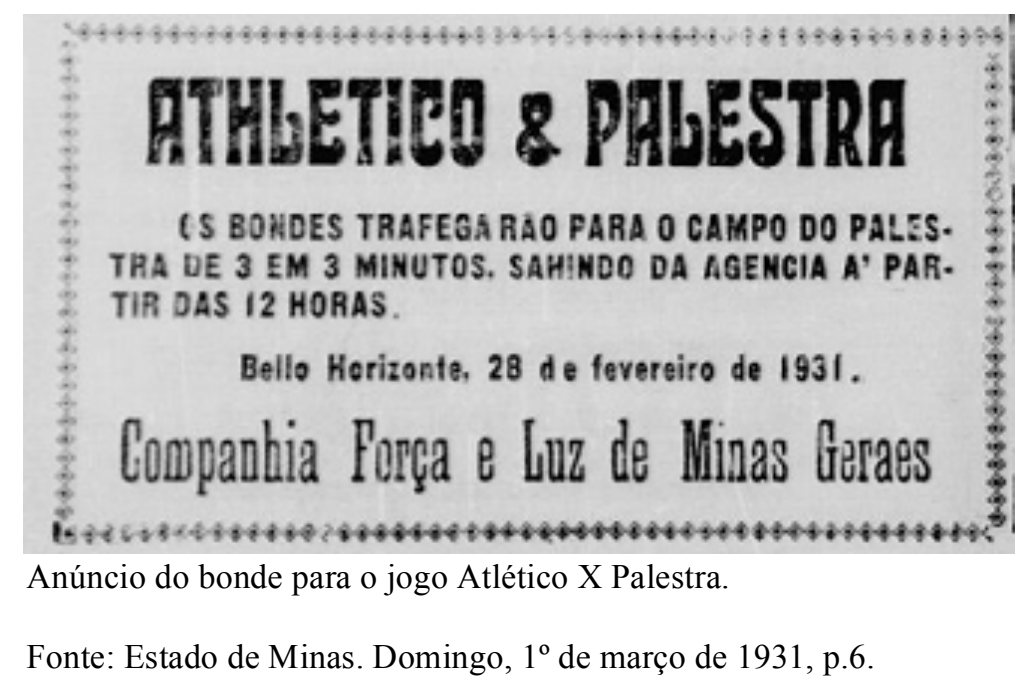

Diante da efervescência futebolística que se apresentava no cotidiano da recémcapital mineira, o Minas Gerais registrou a vida socioesportiva do início da década de 1930 alertando para a impossível separação do homem contemporâneo do esporte, 
independente da classe. "Mormente no Brasil" numa assistência de futebol é que se extravasa as amarras sociais impostas "e se apresentam como realmente são". Motivo da "grande assistencia que os campos de football apanham". Esta crônica ultrapassava o entendimento do futebol como uma simples prática esportiva sem sentido, ela o alçava a um jogo capaz de promover consciência ao homem contemporâneo diante das mazelas sociais da época.

\begin{abstract}
O homem moderno é o menos livre de todos os mortais. Quanto mais se instrue e civiliza, tanto mais estreita lhe é a esteira do convencionalismo que domina a sociedade e sobre a qual esta lhe obriga a ação. A complexidade desconcertante de sua vida, com a qual o homem se debate quotidianamente, aqui vencendo-lhe as arestas, ali cedendo ao seu jugo, absorve-lhe todas as atenções e cuidados, determinando-lhe a atividade incessante e viva de todas as suas energias. (...) Compreendendo assim, está justificado o domínio quase absoluto dos esportes sobre todas as classes. Mormente o football no Brasil, já não há quem não lhe seja um gratuito apologista e quem não procure um estádio para fazer vibrar um pouco as suas emoções. A sociedade exige tributos pesadíssimos e cada um de nós tem dentro de si um menino travesso. É, pois, em uma partida de football que esse menino irá viver umas horas, enquanto desaparece o boneco que a sociedade modelou, porque $o$ entusiasmo que agita uma assistencia é o símbolo eloqüente da revolta contra as exigências sociais. (...) Em um campo de football nós vemos, o magistrado que antes decidira uma causa com a circunspecção a que a toga lhe obriga; o pensador que, no gabinete, é tão impenetrável quanto os problemas metaficos; o financista que faz malabarismo com numeros para pôr em equação a atual crise economica do mundo; o romancista que vê luar com o sol a pino para imprimir a uma pagina amorosa o sentimentalismo exigido pelos incorrigiveis romanticos. E ao lado destes, o engraxate, o cambista, o empregado do comercio, o funcionario. E todos êles, "nobres e plebeus", têm nos gestos, nos gritos, nas expansões, as expansões, os gestos e os gritos do garoto que trazem consigo. É no football, portanto, que os homens se libertam das peias sociais e se apresentam como realmente são. E, tendo o homem necessidade se ser o que é ao menos uma vez por ano, está provada a razao da grande assistencia que os campos de football apanham (dizemos football porque êle é o nosso esporte favorito) (MINAS GERAES, 1931, p. 11).
\end{abstract}

O homem, designado como nobre e plebeu no texto da crônica, é revelado sem liberdade - não a liberdade sonhada pelos escravos de outrora - mas a liberdade que a rotina da lida capitalista o tomou, absorvendo-lhe todas as atenções para a disciplina do trabalho e cada vez mais preso às leis e designações morais que a sociedade lhe impunha. A liberdade integral, para o autor da crônica, só é percebida no campo de 
futebol, local onde se apresentam como realmente são e onde se faz liberar um pouco as suas emoções.

Analisando o texto da crônica notamos que a assistência ao jogo de futebol já evidenciava uma importante manifestação cultural constituinte dos divertimentos citadinos. Chama-nos também a atenção a relação supostamente paradoxal entre os sentidos e as funções atrelados ao futebol. Por meio das fontes consultadas, é possível perceber que, em certo momento, o esporte foi fortemente incentivado e absorvido como possibilidade de formas de educação que se aproximavam a um modelo de civilidade europeia. Ao mesmo tempo, percebe-se o futebol como lugar de contestação das próprias amarras impostas pelos padrões sociais vigentes, permitindo, inclusive, momento de catarse e liberação.

Sobre esta dualidade, Norbert Elias (1994) elabora, em um dado momento de sua obra, uma relação entre o esporte e as emoções vivenciadas no contexto desse universo. Para o autor, é possível perceber a existência de uma relação entres as formas de conflito com formas de interdependências, através de emoções como o prazer e o sofrimento. A constituição das experiências sociais proporcionadas no estádio de futebol, como o torcer, é um processo que pode refletir, em parte, o pensamento desse autor, conforme vislumbrado na ambiguidade das reportagens pesquisadas.

\section{Considerações Finais}

A chegada do futebol em Belo Horizonte, num primeiro momento associado a um mundo aristocrata local teve a intenção de se constituir num marco moderno. Em um momento posterior, (re)significado e popularizado, foi palco para o emergir de novas experiências. 
As páginas dos jornais explicitaram a expectativa pelas partidas mais importantes, organizadas, via de regra, pela Associação Mineira de Chronistas Sportivos ou pela Liga Mineira de Sports Athleticos. Tais partidas eram, comumente, protagonizadas pelo Atlético Mineiro, América ou Palestra Itália, equipes que se firmaram como as mais populares da cidade.

Finalmente, notamos que a afluência de torcedores para os jogos de futebol foi destaque nas seções esportivas dos jornais de Belo Horizonte. Os jogos disputados inspiraram cronistas do cotidiano às mais impactantes conclusões sobre esses acontecimentos tidos como grandiosos, momentos que se assemelhavam a uma procissão no trajeto dos torcedores às canchas esportivas da cidade, tal era a quantidade de pessoas que faziam do futebol prática de divertimento das mais significativas na capital mineira.

\section{REFERÊNCIAS}

ANDRADE, Mário de. Macunaíma, o herói sem nenhum caráter. Rio de Janeiro: Villa Rica Editoras Reunidas Limitada, 1993.

ARALDO Italiano. Terça-feira, 31 de julho de 1923, p. 2.

BERTOLLI FILHO, Cláudio; MEIHY, José Carlos Sebe Bom. Monteiro Lobato e o futebol: um projeto para a elite urbana do começo do século. In: MEIHY, José Carlos Sebe Bom. WITTER, José Sebastião (Org.). Futebol e cultura: coletânea de estudos. São Paulo: Imprensa Oficial; arquivo do Estado, 1982.

COUTO, Euclides de Freitas. Belo Horizonte e o futebol: integração social e identidades coletivas (1897-1927). Dissertação (Mestrado) - Pontifícia Universidade Católica de Minas Gerais, 2003.

DIARIO de Minas. Belo Horizonte, 04 de abril de 1920. Seção Chronica Sportiva, p.2.

DIARIO de Minas. Belo Horizonte, 19 de abril de 1921. Seção Vida Sportiva, p.2.

DIARIO de Minas. Belo Horizonte, 20 de dezembro de 1921. Seção Vida Sportiva, p.2. 
ELIAS, Norbert. O processo civilizador. Rio de Janeiro: Jorge Zahar, 1994. v. 1.

ESTADO de Minas. Belo Horizonte, 01 de março de 1931, p. 6.

O ESTADO de Minas. Belo Horizonte, 04 de janeiro de 1930. Seção Esportes, p. 5.

FONSECA, Coryntho da. O football não merece o título de desporto. Minas Geraes, Belo Horizonte, 04 de janeiro de 1930. Seção Desportos, p. 14.

GOMES, Christianne Luce. Estudos do lazer e geopolítica do conhecimento. Revista Licere, Belo Horizonte, v.14, n.3, setembro de 2011.

GUTERMAN, Marcos. O futebol explica o Brasil: uma história da maior expressão popular do país. São Paulo: Contexto, 2009.

LEVINE, Robert M. Esporte e sociedade: o caso do futebol brasileiro. In: MEIHY, José Carlos Sebe Bom; WITTER, José Sebastião (Org.). Futebol e cultura: coletânea de estudos. São Paulo: Imprensa Oficial; arquivo do Estado, 1982.

MINAS Geraes. Belo Horizonte, 14 de abril de 1921. Seção Sports, p.6.

MINAS Geraes. Belo Horizonte, 11 de novembro de 1921. Seção Desportos, p.6.

MINAS Geraes. Belo Horizonte, 14 de abril de 1922. Seção Esportes, p.7.

MINAS Geraes. Belo Horizonte, 15 de novembro de 1922. Seção Desportos, p.7.

MINAS Geraes. Belo Horizonte, 02 e 03 de junho de 1930. Seção Desportos, p.11.

MINAS Geraes. Belo Horizonte, 16 e 17 de junho de 1930. Seção Desportos, p.13.

MINAS Geraes. Belo Horizonte, 11 de agosto de 1931. Seção Esportes, p.11.

MOURA, Rodrigo Caldeira Bagni. O amadorismo, o profissionalismo, os sururus e outras tramas: o futebol em Belo Horizonte nas décadas de 1920 e 1930. Dissertação (Mestrado em Lazer) Escola de Educação Física, Fisioterapia e Terapia Ocupacional UFMG, Belo Horizontes, 2010.

NAVA, Pedro. Balão cativo. 2. ed. Rio de Janeiro: José Olympio, 1974.

PEREIRA, Leonardo Affonso de Miranda. Footballmania - uma história social do futebol no Rio de Janeiro, 1902-1938. Rio de Janeiro: Nova Fronteira, 2000.

RAMOS, Graciliano. O Estado de São Paulo. São Paulo, 17 de abril de 1994. Caderno D/Especial, p. 2.

RIBEIRO, Raphael Rajão. A bola em meio a ruas alinhadas e a uma poeira infernal: os primeiros anos do futebol em Belo Horizonte (1904 - 1921). Dissertação (Mestrado em História) - Faculdade de Filosofia e Ciências Humanas - UFMG, Belo Horizonte, 2007. 
O futebol em Belo Horizonte e a constituição do campo esportivo (1904-1921). In: SILVA, Sílvio Ricardo da; DEBORTOLI, José Alfredo; SILVA, Tiago Felipe da. O futebol nas Gerais (Org.). Belo Horizonte: Editora UFMG, 2011.

RODRIGUES, Marilita Aparecida Arantes. Constituição e enraizamento do esporte na cidade - Uma prática moderna de lazer na cultura urbana de Belo Horizonte (1894- 1920). Tese (Doutorado) - Faculdade de Filosofia e Ciências Humanas/UFMG, 2006.

SEVCENKO, Nicolau. O prelúdio republicano, astúcias da ordem e ilusões do progresso. In: SEVCENKO, Nicolau (Org.). História da vida privada no Brasil República: da Belle Époque à era do rádio. São Paulo: Companhia das Letras, 1998. v. 3.

SILVA, Giselda Brito. No entre guerra, a situação dos integralistas na implantação do estado novo de Getúlio Vargas. Proj. História, São Paulo, n. 30, p. 229-241, junho de 2005.

SILVA, Marcelino Rodrigues. Picadinho de raposa com sopa de galo. In: SILVA, Silvio Ricardo; DEBORTOLI, José Alfredo Oliveira de; SILVA, Tiago Felipe da. (Org.); O futebol nas gerais. Belo Horizonte: Editora UFMG, 2012.

SOARES, Antônio Jorge G.; LOVISOLO, Hugo Rodolfo. O futebol é fogo de palha: a "profecia" de Graciliano Ramos. Pesquisa de Campo. Rio de Janeiro, n.5, p.7-20, 1997.

SOUZA NETO, Georgino de. A invenção do torcer em Belo Horizonte: da assistência ao pertencimento clubístico (1904 - 1930). Dissertação (Mestrado em Lazer) - Escola de Educação Física, Fisioterapia e Terapia Ocupacional - UFMG, Belo Horizonte, 2010 .

VIEIRA, Carlos Eduardo. Jornal diário como fonte e como tema para a pesquisa em História da Educação: um estudo da relação entre imprensa, intelectuais e modernidade nos anos de 1920. In: OLIVEIRA, Marcus Aurélio Taborda de (Org.). Cinco estudos em história da educação. Belo Horizonte: Autêntica Editora, 2007. p. 11-40.

VILHENA, Kellen Nogueira. Entre "sãns expansões do espírito" e "sarrilhos dos diabos": lazer, divertimento e vadiagem nas representações da imprensa em Belo Horizonte (1895 - 1922). Dissertação (Mestrado em Lazer) - Escola de Educação Física, Fisioterapia e Terapia Ocupacional - UFMG, Belo Horizonte, 2008.

ZILLER, Adelchi Leonello. Enciclopédia Atlético de todos os tempos - a vida, as lutas, as glórias do Clube Atlético Mineiro, o campeoníssimo das Gerais. Belo Horizonte, 1997 (s.n.).

\section{Endereço dos Autores:}

Sílvio Ricardo da Silva

Departamento de Educação Física 
Escola de educação física, fisioterapia e terapia Ocupacional UFMG - Universidade Federal de Minas Gerais

Av. Pres. Antônio Carlos, 6627 Campus - Pampulha

Belo Horizonte - MG - 31270-901

Endereço Eletrônico: prof.srs@gmail.com 